\title{
The association of six polymorphisms of five genes involved in three steps of nucleotide excision repair pathways with hepatocellular cancer risk
}

\author{
Bengang Wang ${ }^{1,2, *}$, Qian $X_{u^{1}{ }^{1, *} \text {, Huai-wei Yang }}{ }^{1}$, Li-ping Sun ${ }^{1}$, Yuan Yuan ${ }^{1}$ \\ ${ }^{1}$ Tumor Etiology and Screening Department of Cancer Institute and General Surgery, The First Affiliated Hospital of China \\ Medical University, and Key Laboratory of Cancer Etiology and Prevention (China Medical University), Liaoning Provincial \\ Education Department, Shenyang 110001, China \\ ${ }^{2}$ Hepatobiliary Surgery Department of General Surgery Institute, The First Affiliated Hospital of China Medical University, \\ Shenyang 110001, China \\ *These authors contributed equally to this work
}

Correspondence to: Yuan Yuan, e-mail: yyuan@mail.cmu.edu.cn

Keywords: nucleotide excision repair, single nucleotide polymorphism, hepatocellular cancer, interaction

Received: September 07, 2015

Accepted: February 15, 2016

Published: March 07, 2016

\section{ABSTRACT}

Background: Hundreds of single nucleotide polymorphisms (SNPs) of the genes encoding nucleotide excision repair (NER) proteins are involved in every step of the DNA recognition-unwinding-incision process, which may affect cancer risk. However, only a limited number of studies have examined the association of NER SNPs with hepatocellular cancer (HCC) risk.

Results: In screening stage, single-locus analysis showed that six SNPs in five genes were associated with HCC risk, including three risk SNPs (XPA rs10817938, $X P C$ rs1870134 and ERCC2 rs238417) and three protective SNPs (ERCC1 rs2298881 and rs3212961, and ERCC5 rs873601). In verification stage, only XPC rs1870134 was verified to be associated with HCC risk $\left(P=4.7 \times 10^{-4}\right)$. Furthermore, multivariate logistic regression and MDR analysis consistently revealed a gene-gene interaction among ERCC1 rs2298881 and XPC rs1870134 SNPs associated with HCC risk ( $P_{\text {interaction }}$ $=0.023$ ). When analyzing the effect of the positive SNP on the mRNA expression, we found XPC rs1870134 GG genotype which was associated with an increased HCC risk showed lower XPC mRNA expression.

Methods: This study designed as "screening-verification" experiments and included a total of 1472 participants ( 570 HCC patients vs. 902 controls). We explored 39 SNPs in eight genes involved in NER Pathways, including XPA, XPC, DDB2, ERCC3, ERCC2, ERCC1, ERCC4 and ERCC5, using Sequenom MassARRAY and KASPar platform. Eighty-six cases of HCC and the neighboring noncancerous tissues were subjected to the measurement of mRNA expression level of the promising gene.

Conclusion: XPC promoter rs1870134 SNP and SNP-SNP interaction were associated with HCC risk.

\section{INTRODUCTION}

Hepatocellular cancer (HCC) is the sixth most common type of cancer and the third most frequent cause of cancer death worldwide $[1,2]$. The incidence of HCC is associated with environmental and hereditary factors, therefore the risk of developing disease varies between patients. To date, several single nucleotide polymorphisms (SNPs) in some genes involved in oxidative stress, metabolism and inflammation pathways, have been proved to be associated with HCC risk [3]. These SNPs have great significance for the selection of individuals who benefit from specific preventative measures [3].

DNA repair systems include nucleotide excision repair (NER), base excision repair, mismatch repair, and double-strand break repair [4]. Among these repair systems, the NER system is most frequently associated with cancer [5]. Ishikawa et al. previously reported that the 
DNA repair system, especially the NER pathway, played a vital role in protection against human cancer [6].

The NER pathway is composed of DNA recognitionrelated proteins including $X P A, X P C$, and $D D B 2$; DNA unwinding-related proteins such as $X P B(E R C C 3)$ and $X P D$ (ERCC2); and DNA incision-related proteins, for instance ERCC1, XPF (ERCC4), and XPG (ERCC5). Hundreds of SNP variants of the genes encoding these NER proteins are involved in every step of the DNA recognition-unwinding-incision process, which may increase or decrease protein expression and function $[7,8]$. However, only a limited number of studies have examined the association of NER SNPs with HCC risk, although a few studies focused on single exon SNPs such as XRCC1 Arg399Gln, XRCC3 Thr241Met, and XPD Lys751Gln have been reported [9-12]. And there was a meta-analysis investigating the association of NER SNPs with risks of several kinds of cancers [13] without hepatocellular cancer, which maybe because that few studies were performed about the association of NER SNPs with HCC risk. Thus, a systematic and comprehensive evaluation of the relationship between these SNPs and HCC risk are urgently required, which could provide a comprehensive understanding of the implications of NER biological pathways involved in hepatocarcinogenesis, as well as screening the most significant functional SNP variants and potential biomarkers for predicting HCC risk.

In the present study, we adopted candidate gene association study strategy with selected 39 potentially functional tag SNPs (tagSNPs) in eight genes involved in NER pathways: XPA, XPC, DDB2, ERCC1, ERCC2, $E R C C 3, E R C C 4$ and ERCC5. We determined whether these genes were associated with HCC in the second verification stage, and for the promising SNPs we investigated the effects of the SNPs on the mRNA expression of the corresponding genes. We aimed to identify predictive biomarkers for $\mathrm{HCC}$ risk and tried to establish an experimental basis to improve understanding of the etiology and the mechanism of HCC.

\section{RESULTS}

\section{The association of SNPs in NER pathway genes with hepatocellular cancer risk}

The demographic characteristics of $\mathrm{HCC}$ and control subjects are shown in Supplementary Table S1. All polymorphism genotype distributions in cases and controls are shown in Supplementary Table S2, including 39 SNPs in eight genes (recognition-related: $X P A$ rs10817938, rs3176629, rs3176658, rs2808668; $X P C$ rs2607775, rs 1870134, rs2228000, rs2228001, rs2470352; DDB2 rs2029298, rs830083, rs3781619, rs326222; unwinding-related: ERCC3 rs4150441, rs4150448, rs4150506; ERCC2 rs238406, rs50871, rs50872, rs238417, rs1052555, rs13181; incision-related: ERCC1 rs2298881, rs11615, rs3212955, rs3212961, rs3212986, rs735482; ERCC4 rs254942, rs1799801, rs2276464; and ERCC5 rs2094258, rs751402, rs2296147, rs1047768, rs4150291, rs2228959, rs4150383, and rs873601). Among them, most SNPs conformed to Hardy-Weinberg equilibrium (HWE) including SNPs in stage 1 and 2, except for DDB2 rs326222 $\left(P_{\mathrm{HWE}}=0.022\right)$, ERCC2 $\mathrm{rs} 50871\left(P_{\mathrm{HWE}}=5 \times 10^{-7}\right)$, ERCC5 rs751402 $\left(P_{\mathrm{HWE}}=0.018\right)$ and $\mathrm{rs} 2228959\left(P_{\mathrm{HWE}}\right.$ $=0.013)$ in stage 1 . Therefore these four SNPs were discarded in further association analysis.

Among these 39 SNPs, six SNPs in five genes were associated with $\mathrm{HCC}$ risk in stage 1, including three risk SNPs (XPA rs10817938, XPC rs 1870134 and ERCC2 rs238417) and three protective SNPs (ERCC1 rs2298881 and rs3212961, and $E R C C 5$ rs873601). We further analyzed these promising SNPs and found that the XPA rs 10817938 variant $\mathrm{CC}$ genotype showed an increased risk of HCC (odds ratio $[\mathrm{OR}]=2.52$ and 2.66, respectively; Table 1) when compared with TT wild-type and TT + TC genotype. The ERCC2 rs238417 variant CC genotype also showed an increased risk $(\mathrm{OR}=1.77$ and 1.33 , respectively) under the allelic model. And the XPC rs 1870134 variant GG $+\mathrm{GC}$ genotype showed an increased risk for $\mathrm{HCC}(\mathrm{OR}=2.78)$ when compared with CC genotype. By contrast, the ERCC5 rs873601 variant AA genotype had a decreased risk for $\mathrm{HCC}(\mathrm{OR}=0.58$ and 0.59 , respectively $)$ when compared with GG wild-type and under the recessive model. Two positive SNPs were identified in $E R C C 1$, rs2298881 and rs3212961, which were associated with a decreased HCC risk $(\mathrm{OR}=0.64$ and 0.60 , respectively, Table 1$)$ when the heterozygote was compared with the wild-type.

In the verification stage, as the $P$ value was cut-off for 0.00128 , we only found that the $X P C$ rs $1870134 \mathrm{GG}$ genotype showed a significant increased risk for HCC $\left(P=4.7 \times 10^{-4}, \mathrm{OR}=1.67\right)$ when compared with $\mathrm{CC}+\mathrm{GC}$ genotype. We merged this two stages for a meta-analysis, and also found this $X P C$ rs $1870134 \mathrm{GG}$ genotype showed a significant increased risk for $\mathrm{HCC}(P=0.001, \mathrm{OR}=1.45$, Table 1).

And we also analyzed the association of the positive $X P C$ rs1870134 SNP with the clinical features of HCC about smoking, drinking, family history, $\mathrm{HBV}$ and $\mathrm{HCV}$ infection status and histopathology classification, but found no significant association (Supplementary Table S3).

\section{The association of haplotype in NER pathway genes with hepatocellular cancer risk}

We considered that haplotypes with a frequency less than 0.03 would be excluded from analysis. Six haplotypes in four genes were found to be associated with HCC risk.

Compared with other haplotypes, patients with the A-C-A-T haplotype of DDB2 rs2029298-rs830083rs3781619-rs326222 showed a 2.29-fold increased HCC 
Table 1: The association of promising SNPs of NER pathway genes with hepatocellular cancer risk

\begin{tabular}{|c|c|c|c|c|c|c|c|c|c|c|c|c|}
\hline \multirow{3}{*}{ Gene } & \multirow{3}{*}{ SNP } & \multirow{3}{*}{ Genotype } & \multicolumn{4}{|c|}{ Stage 1} & \multicolumn{4}{|c|}{ Stage 2} & \multicolumn{2}{|r|}{ Meta } \\
\hline & & & Cases (\%) & Controls (\%) & $p^{a}$ & OR $(95 \% \mathrm{CI})$ & Cases (\%) & $\begin{array}{c}\text { Controls } \\
(\%)\end{array}$ & $p^{a}$ & OR(95\%CI) & $P^{n}$ & OR $(95 \% \mathrm{CI})$ \\
\hline & & & $n=169$ & $n=501$ & & & $n=401$ & $n=401$ & & & & \\
\hline \multicolumn{13}{|c|}{ Recognition-related } \\
\hline \multirow[t]{6}{*}{ XPA } & \begin{tabular}{|l|} 
rs10817938 \\
\end{tabular} & & & & & & $n=353$ & $n=379$ & & & & \\
\hline & & TT & $105(62.1)$ & $311(62.1)$ & & 1(Ref.) & $208(58.9)$ & $241(63.6)$ & & 1 (Ref.) & & \\
\hline & & $\mathrm{TC}$ & $51(30.2)$ & $172(34.3)$ & 0.525 & $0.88(0.60-1.30)$ & $129(36.5)$ & $124(32.7)$ & 0.263 & $1.19(0.88-1.63)$ & 0.537 & $1.08(0.85-1.36)$ \\
\hline & & $\mathrm{CC}$ & $13(7.7)$ & $15(3.0)$ & 0.020 & $2.52(1.16-5.49)$ & $16(4.5)$ & $14(3.5)$ & 0.098 & $2.04(0.88-4.73)$ & 0.038 & $1.76(1.03-3.01)$ \\
\hline & & $\mathrm{CC}+\mathrm{CT}$ vs. TT & & & 0.956 & $1.01(0.70-1.45)$ & & & 0.146 & $1.25(0.93-1.69)$ & 0.260 & $1.14(0.91-1.42)$ \\
\hline & & \begin{tabular}{|l|} 
CC vs. TT+TC \\
\end{tabular} & & & 0.012 & $2.66(1.24-5.74)$ & & & 0.136 & $1.88(0.82-4.33)$ & 0.045 & $1.72(1.01-2.91)$ \\
\hline \multirow[t]{6}{*}{ XPC } & \begin{tabular}{|l|} 
rs1870134 \\
\end{tabular} & & & & & & $n=359$ & $n=381$ & & & & \\
\hline & & GG & $88(52.1)$ & $257(51.3)$ & & 1 (Ref.) & $230(64.1)$ & $197(51.7)$ & & 1 (Ref.) & & \\
\hline & & $\mathrm{GC}$ & $76(45.0)$ & $204(40.7)$ & 0.654 & $1.09(0.76-1.56)$ & $114(31.8)$ & $160(42.0)$ & 0.001 & $0.60(0.44-0.82)$ & 0.009 & $0.74(0.59-0.93)$ \\
\hline & & $\mathrm{CC}$ & $5(3.0)$ & $39(7.8)$ & \begin{tabular}{|l|l|}
0.048 \\
\end{tabular} & $0.39(0.14-0.99)$ & $15(4.2)$ & $24(6.3)$ & 0.067 & $0.53(0.27-1.05)$ & 0.002 & $0.44(0.26-0.75)$ \\
\hline & & GG vs. $\mathrm{CC}+\mathrm{GC}$ & & & 0.869 & $1.03(1.01-1.47)$ & & & $4.7 \times 10^{-4}$ & $1.67(1.25-2.27)$ & 0.001 & $1.45(1.15-1.79)$ \\
\hline & & GG+GC vs. $\mathrm{CC}$ & & & 0.034 & $2.78(1.09-7.14)$ & & & 0.214 & $1.52(0.78-2.94)$ & 0.010 & $1.96(0.56-3.33)$ \\
\hline \multicolumn{13}{|c|}{ Unwinding-related } \\
\hline \multirow[t]{6}{*}{ XPD(ERCC2) } & rs238417 & & & & & & $n=345$ & $n=372$ & & & & \\
\hline & & GG & $39(23.1)$ & $149(29.7)$ & & 1 (Ref.) & $127(36.8)$ & $148(39.8)$ & & 1 (Ref.) & & \\
\hline & & GC & $87(51.5)$ & $248(49.5)$ & 0.191 & \begin{tabular}{|l}
$1.33(0.87-2.05)$ \\
\end{tabular} & $158(45.8)$ & $155(41.7)$ & 0.249 & $1.21(0.87-1.68)$ & 0.491 & $1.09(0.85-1.40)$ \\
\hline & & $\mathrm{CC}$ & $43(25.4)$ & $90(18.0)$ & 0.028 & $1.77(1.06-2.95)$ & $60((17.4)$ & $69(18.5)$ & 0.796 & $1.06(0.69-1.62)$ & 0.330 & $1.17(0.85-1.60)$ \\
\hline & & $\mathrm{CC}+\mathrm{GC}$ vs. GG & & & 0.068 & $1.46(0.97-2.20)$ & & & 0.310 & $1.17(0.86-1.59)$ & 0.349 & $1.12(0.86-1.41)$ \\
\hline & & \begin{tabular}{|c|} 
CC vs. $\mathrm{GG}+\mathrm{GC}$ \\
\end{tabular} & & & 0.056 & $1.50(0.99-2.27)$ & & & 0.794 & $0.95(0.65-1.40)$ & 0.437 & $1.12(0.85-1.47)$ \\
\hline \multicolumn{13}{|c|}{ Incision-related } \\
\hline \multirow[t]{12}{*}{ ERCC1 } & rs 2298881 & & & & & & $n=329$ & $n=388$ & & & & \\
\hline & & $\mathrm{CC}$ & 79 (46.7) & $194(38.7)$ & & 1 (Ref.) & 104 (31.6) & $145(37.4)$ & & 1 (Ref.) & & \\
\hline & & $\mathrm{CA}$ & $58(34.3)$ & $224(44.7)$ & \begin{tabular}{|l|l|}
0.027 \\
\end{tabular} & \begin{tabular}{|l|l|}
$0.64(0.44-0.95)$ \\
\end{tabular} & $163(49.5)$ & $191(49.2)$ & 0.302 & $1.19(0.86-1.65)$ & 0.953 & $0.99(0.78-1.27)$ \\
\hline & & $\mathrm{AA}$ & 32 (18.9) & $81(16.2)$ & 0.929 & \begin{tabular}{|l}
$0.98(0.60-1.59)$ \\
\end{tabular} & $62(18.8)$ & $52(13.4)$ & 0.020 & $1.71(1.09-2.68)$ & 0.096 & $1.31(0.95-1.81)$ \\
\hline & & $\mathrm{CA}+\mathrm{AA}$ vs. $\mathrm{CC}$ & & & 0.076 & $0.73(0.51-1.03)$ & & & 0.100 & $1.30(0.95-1.77)$ & 0.563 & $1.07(0.85-1.34)$ \\
\hline & & AA vs. $\mathrm{CC}+\mathrm{CA}$ & & & 0.427 & $1.20(0.76-1.89)$ & & & 0.036 & $1.54(1.03-2.31)$ & 0.061 & $1.32(0.99-1.77)$ \\
\hline & rs 3212961 & & & & & & $n=367$ & $n=388$ & & & & \\
\hline & & $\mathrm{CC}$ & 64 (37.9) & $143(28.5)$ & & 1 (Ref.) & $124(33.8)$ & \begin{tabular}{|l|}
$119(30.7)$ \\
\end{tabular} & & 1 (Ref.) & & \\
\hline & & $\mathrm{CA}$ & 66 (39.1) & $251(50.1)$ & 0.012 & \begin{tabular}{|l|l|}
$0.60(0.40-0.89)$ \\
\end{tabular} & \begin{tabular}{|l|}
$158(43.1)$ \\
\end{tabular} & $188(48.5)$ & 0.211 & $0.81(0.58-1.13)$ & 0.008 & $0.72(0.56-0.92)$ \\
\hline & & $\mathrm{AA}$ & $39(23.1)$ & $106(21.2)$ & 0.422 & $0.83(0.51-1.32)$ & $85(23.2)$ & $81(20.9)$ & 0.889 & $1.03(0.69-1.53)$ & 0.600 & $0.92(0.69-1.24)$ \\
\hline & & $\mathrm{CA}+\mathrm{AA}$ vs. $\mathrm{CC}$ & & & \begin{tabular}{|l|}
0.028 \\
\end{tabular} & $0.66(0.46-0.96)$ & & & 0.392 & $0.88(0.64-1.19)$ & 0.032 & $0.78(0.62-0.98)$ \\
\hline & & AA vs. $\mathrm{CC}+\mathrm{CA}$ & & & 0.612 & \begin{tabular}{|l}
$1.11(0.73-1.69)$ \\
\end{tabular} & & & 0.399 & $1.16(0.82-1.64)$ & 0.353 & $1.13(0.87-1.46)$ \\
\hline \multirow[t]{6}{*}{ XPG(ERCC5) } & rs873601 & & & & & & $n=369$ & $n=394$ & & & & \\
\hline & & GG & $54(32.0)$ & $142(28.3)$ & & 1 (Ref.) & \begin{tabular}{|l|}
$109(29.5)$ \\
\end{tabular} & $129(32.7)$ & & 1 (Ref.) & & \\
\hline & & GA & $87(51.5)$ & $231(46.1)$ & 0.966 & $0.99(0.66-1.48)$ & $184(49.9)$ & 177(44.9) & 0.223 & $1.23(0.88-1.71)$ & 0.414 & $1.11(0.87-1.42)$ \\
\hline & & $\mathrm{AA}$ & $28(16.6)$ & $126(25.1)$ & \begin{tabular}{|l|l|}
0.041 \\
\end{tabular} & \begin{tabular}{|l|l|}
$0.58(0.35-0.98)$ \\
\end{tabular} & $76(20.6)$ & $88(22.3)$ & 0.897 & $1.03(0.69-1.53)$ & 0.165 & $0.81(0.60-1.09)$ \\
\hline & & $\begin{array}{c}\mathrm{AA}+\mathrm{GA} \text { vs. } \\
\text { GG }\end{array}$ & & & 0.389 & $0.85(0.58-1.24)$ & & & 0.350 & $1.16(0.85-1.58)$ & 0.963 & $1.01(0.80-1.27)$ \\
\hline & & AA vs. GG+GA & & & 0.022 & \begin{tabular}{|l}
$0.59(0.37-0.93)$ \\
\end{tabular} & & & 0.588 & $0.91(0.64-1.29)$ & 0.038 & $0.76(0.58-0.99)$ \\
\hline
\end{tabular}

a, $P$ value was calculated by adjusted age and sex.

risk $(P=0.007,95 \% \mathrm{CI}=1.23-4.25)$, while patients with the G-C-C-C-T-C-G-G haplotype of ERCC5 rs2094258-rs751402-rs2296147-rs1047768-rs4150291rs2228959-rs4150383-rs873601 showed a significant protective function for HCC $(P=0.015, \mathrm{OR}=0.41,95 \%$ $\mathrm{CI}=0.20-0.86)$. As shown in Table 1 , the promising SNPs associated with HCC risk were ERCC1 rs2298881rs3212961, and we only analyzed haplotypes composed of these positive SNPs instead of the analysis for ERCC1 rs2298881-rs11615-rs3212955-rs3212961-rs3212986rs735482, which simplified the analysis and obtained similar results to a complete analysis of all six SNPs. The A-C haplotype of ERCC1 rs2298881-s3212961 had a protective function for $\mathrm{HCC}$ risk $(\mathrm{OR}=0.70)$, while the $\mathrm{C}$-C haplotype showed an increased risk $(\mathrm{OR}=1.47$; Table 2$)$.
Linkage disequilibrium data composed of D' and $r^{2}$ for these eight polymorphisms are shown in Supplementary Figure S1.

\section{Gene-gene interaction models for polymorphisms in NER pathways}

In order to analyze the best interaction model composed of the six promising SNPs in NER pathways genes in stage 2, we used MDR software to select the best model for gene-gene interaction (Table 3). To predict HCC risk, the best interaction model selected from the six positive SNPs was the four-factor model including ERCC1 rs2298881-XPC rs1870134-ERCC2 rs238417ERCC5 rs873601 SNPs, which yielded the highest testing 
Table 2: The association of haplotype of each gene in NER pathways with hepatocellular cancer risk

\begin{tabular}{|c|c|c|c|c|}
\hline Haplotype & Case (\%) & Control (\%) & $P$ & OR (95\% CI) \\
\hline \multicolumn{5}{|l|}{$\begin{array}{l}\text { Stage } 1 \\
\end{array}$} \\
\hline \multicolumn{5}{|l|}{$\mathbf{X P A}^{\mathbf{a}}$} \\
\hline $\mathrm{C} \mathrm{C} \mathrm{T}$ & $75.83(22.4)$ & $199.47(20.2)$ & 0.376 & $1.15(0.85-1.54)$ \\
\hline T C C & $168.83(49.9)$ & $490.28(49.6)$ & 0.906 & $1.02(0.79-1.30)$ \\
\hline T C T & $63.17(18.7)$ & $201.56(20.4)$ & 0.502 & $0.90(0.66-1.23)$ \\
\hline T T T & $29.00(8.6)$ & $94.14(9.5)$ & 0.607 & $0.89(0.58-1.38)$ \\
\hline \multicolumn{5}{|l|}{$\mathrm{XPC}^{\mathrm{b}}$} \\
\hline $\mathrm{C} \mathrm{C} \mathrm{C} \mathrm{A}$ & $83.99(24.8)$ & $273.12(27.9)$ & 0.273 & $0.85(0.64-1.13)$ \\
\hline $\mathrm{C} \mathrm{G} \mathrm{C} \mathrm{C}$ & $125.90(37.2)$ & $350.22(35.7)$ & 0.630 & $1.07(0.82-1.38)$ \\
\hline $\mathrm{CGTA}$ & $105.09(31.1)$ & 306.45 (31.3) & 0.937 & $0.99(0.76-1.29)$ \\
\hline G GCA & $18.00(5.3)$ & $34.07(3.5)$ & 0.134 & $1.56(0.87-2.80)$ \\
\hline \multicolumn{5}{|l|}{ DDB2 $^{c}$} \\
\hline $\mathrm{ACAT}$ & $18.45(5.5)$ & $24.29(2.4)$ & 0.007 & $2.29(1.23-4.25)$ \\
\hline A G G C & $91.43(27.2)$ & $250.03(25.2)$ & 0.536 & $1.09(0.83-1.45)$ \\
\hline $\mathrm{AGGT}$ & $11.47(3.4)$ & $34.04(3.4)$ & 0.959 & $0.98(0.50-1.94)$ \\
\hline GCAT & $182.55(54.3)$ & $586.56(59.1)$ & 0.075 & $0.80(0.62-1.02)$ \\
\hline G G GC & $15.57(4.6)$ & $27.83(2.8)$ & 0.112 & $1.66(0.88-3.13)$ \\
\hline G G G T & $12.53(3.7)$ & $46.03(4.6)$ & 0.459 & $0.79(0.42-1.49)$ \\
\hline \multicolumn{5}{|l|}{$\mathrm{ERCC3}^{\mathrm{d}}$} \\
\hline $\mathrm{AAC}$ & $45.00(13.3)$ & $97.98(10.0)$ & 0.102 & $1.37(0.94-2.00)$ \\
\hline $\mathrm{AG} \mathrm{T}$ & $94.00(27.8)$ & $307.00(31.2)$ & 0.189 & $0.83(0.63-1.10)$ \\
\hline G G C & $197.00(58.3)$ & $559.98(56.9)$ & 0.848 & $1.03(0.80-1.32)$ \\
\hline \multicolumn{5}{|l|}{$\mathrm{ERCC2}^{\mathrm{e}}$} \\
\hline G G C G C T & $15.63(4.6)$ & $98.40(10.1)$ & 0.001 & $0.42(0.24-0.72)$ \\
\hline G G T G C T & $7.98(2.4)$ & $29.70(3.1)$ & 0.469 & $0.75(0.34-1.65)$ \\
\hline G T C G C T & $70.07(20.7)$ & $243.34(25.1)$ & 0.065 & $0.75(0.55-1.02)$ \\
\hline G T C G T G & $17.12(5.1)$ & $21.31(2.2)$ & 0.009 & $2.33(1.22-4.46)$ \\
\hline G T T G C T & $31.77(9.4)$ & $66.46(6.9)$ & 0.154 & $1.38(0.89-2.15)$ \\
\hline T G C C C T & $50.08(14.8)$ & $125.89(13.0)$ & 0.475 & $1.14(0.80-1.63)$ \\
\hline T T C C C T & $83.02(24.6)$ & $186.46(19.2)$ & 0.054 & $1.34(0.99-1.81)$ \\
\hline T T C G C T & $8.16(2.4)$ & $33.87(3.5)$ & 0.303 & $0.67(0.31-1.45)$ \\
\hline T T T C C T & $20.03(5.9)$ & $46.96(4.8)$ & 0.487 & $1.21(0.71-2.08)$ \\
\hline \multicolumn{5}{|l|}{ ERCC1 $^{g}$} \\
\hline ACAAGC & $117.91(35.1)$ & $379.68(38.4)$ & 0.256 & $0.86(0.66-1.12)$ \\
\hline A C G C TA & $22.99(6.8)$ & $107.79(10.9)$ & 0.030 & $0.60(0.37-0.95)$ \\
\hline A T A C GA & $23.94(7.1)$ & $79.90(8.1)$ & 0.569 & $0.87(0.54-1.40)$ \\
\hline$\overline{\mathrm{CCGCTA}}$ & $71.68(21.3)$ & $176.21(17.8)$ & 0.150 & $1.26(0.92-1.72)$ \\
\hline C TACGA & $63.00(18.8)$ & $137.02(13.9)$ & 0.029 & $1.45(1.04-2.02)$ \\
\hline \multicolumn{5}{|l|}{ ERCC1 $^{\mathrm{h}, \mathrm{k}}$} \\
\hline A-A & $126.00(37.3)$ & $397.00(39.9)$ & 0.401 & $0.90(0.70-1.16)$ \\
\hline $\mathrm{A}-\mathrm{C}$ & $54.00(16.0)$ & $213.00(21.4)$ & 0.032 & $0.70(0.50-0.97)$ \\
\hline C-A & $18.00(5.3)$ & $62.00(6.2)$ & 0.547 & $0.85(0.49-1.45)$ \\
\hline
\end{tabular}




\begin{tabular}{|l|c|c|c|c|}
\hline C-C & $140.00(41.4)$ & $324.00(32.5)$ & 0.003 & $1.47(1.14-1.89)$ \\
\hline ERCC4 $^{\mathbf{1}}$ & & & & \\
\hline C T G & $76.96(22.9)$ & $213.55(21.9)$ & 0.722 & $1.06(0.79-1.42)$ \\
\hline T C C & $69.96(20.8)$ & $201.96(20.7)$ & 0.986 & $1.00(0.74-1.36)$ \\
\hline T T G & $188.04(56.0)$ & $553.45(56.8)$ & 0.754 & $0.96(0.75-1.23)$ \\
\hline ERCC5 & & & & \\
\hline A C T T A C G G & $128.41(38.2)$ & $343.38(37.2)$ & 0.967 & $1.01(0.77-1.31)$ \\
\hline G C C C A C G A & $39.12(11.6)$ & $99.23(10.8)$ & 0.751 & $1.07(0.72-1.58)$ \\
\hline G C C C T C G A & $8.48(2.5)$ & $53.16(5.8)$ & $\mathbf{0 . 0 1 5}$ & $\mathbf{0 . 4 1}(\mathbf{0 . 2 0}-\mathbf{0 . 8 6})$ \\
\hline G C C C T C G G & $10.20(3.0)$ & $31.49(3.4)$ & 0.691 & $0.87(0.42-1.77)$ \\
\hline G C T C A C G G & $25.26(7.5)$ & $58.60(6.4)$ & 0.525 & $1.17(0.72-1.90)$ \\
\hline G T T T A A G A & $10.65(3.2)$ & $33.68(3.7)$ & 0.633 & $0.84(0.42-1.70)$ \\
\hline G T T T A C A A & $22.72(6.8)$ & $60.94(6.6)$ & 0.999 & $1.00(0.61-1.65)$ \\
\hline G T T T A C G A & $54.18(16.1)$ & $144.30(15.7)$ & 0.960 & $1.01(0.72-1.42)$ \\
\hline G T T T A C G G & $21.07(6.3)$ & $34.06(3.7)$ & 0.058 & $1.71(0.98-2.99)$ \\
\hline Stage 2 & & & & \\
\hline ERCC1 & & & \\
\hline A-A & & $657.78(37.5)$ & 0.430 & $1.07(0.91-1.25)$ \\
\hline C-A & $387(39.0)$ & $140.22(8.0)$ & 0.113 & $0.78(0.57-1.06)$ \\
\hline C-C & $63.1(6.3)$ & $940.78(53.6)$ & 0.603 & $0.96(0.82-1.12)$ \\
\hline
\end{tabular}

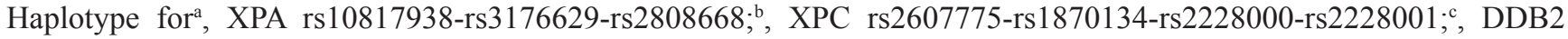
rs2029298-rs830083-rs3781619-rs326222; ${ }^{\text {d }}$ ERCC3 rs4150441-rs4150448-rs4150506; ${ }^{e}$, ERCC2 rs238406-rs50871rs50872-rs238417-rs1052555-rs13181; g,ERCC1 rs2298881-rs11615-rs3212955-rs3212961-rs3212986-rs735482; h,ERCC1 rs2298881-rs3212961; ;, ERCC4 rs254942-rs1799801-rs2276464; ;, ERCC5 rs2094258-rs751402-rs2296147-rs1047768rs4150291-rs2228959-rs4150383-rs873601. k,ERCC1 rs2298881-rs3212961 according to the main analysis in Table 1, we further simplified the analysis for ERCC1 and ERCC2 haplotype and only analyzed the haplotype of the positive ERCC1 rs2298881-rs3212961, which got a similar result with the full one.

Table 3: Gene-gene interaction models for polymorphisms in NER pathways for hepatocellar cancer risk by MDR analysis

\begin{tabular}{|c|c|c|c|c|c|}
\hline Model & $\begin{array}{l}\text { Training Bal. } \\
\text { Acc. }\end{array}$ & $\begin{array}{l}\text { Testing Bal. } \\
\text { Acc. }\end{array}$ & Sign Test $(p)$ & $\begin{array}{c}\text { CV } \\
\text { Consistency }\end{array}$ & $\begin{array}{c}P \text { for } \\
\text { permutation test }\end{array}$ \\
\hline XPC rs 18701343 & 0.5798 & 0.5803 & $8(0.0547)$ & $10 / 10$ & 0.0190 \\
\hline ERCC1 rs2298881-XPC rs1870134b & 0.5974 & 0.5977 & $9(0.0107)$ & $10 / 10$ & $0.0010-0.0020$ \\
\hline $\begin{array}{l}\text { ERCC1 rs2298881-ERCC1 rs3212961- } \\
\text { XPC rs1870134 }\end{array}$ & 0.6061 & 0.5689 & $9(0.0107)$ & $4 / 10$ & 0.0640 \\
\hline $\begin{array}{|ll|}\text { ERCC1 rs2298881-XPC rs1870134- } \\
\text { ERCC2 } \\
\text { rs238417-ERCC5 rs873601a }\end{array}$ & 0.6218 & 0.6001 & $10(0.0010)$ & $10 / 10$ & $0.0010-0.0020$ \\
\hline
\end{tabular}

Note: The best model was selected as the one with the maximum testing accuracy and maximum CV Consistency. ${ }^{a}$ In this study, the best interaction model was the four-factor model including ERCC1 rs2298881-XPC rs1870134-ERCC2 rs238417ERCC5 rs873601 polymorphisms. ${ }^{b}$, the second best interaction model was the two-factor model including ERCC1 rs2298881XPC rs1870134 polymorphisms.

accuracy of 0.6001 and the maximal CV consistency of $10 / 10$ (significant test $P=0.0010$, and $P$ for permutation test $=0.0010-0.0020$ ). And the second interaction model selected was the two-factor model including ERCC1 rs2298881-XPC rs1870134, which yielded the highest testing accuracy of 0.5977 and the maximal $\mathrm{CV}$ consistency of 10/10 (significant test $P=0.0107$, and $P$ for permutation test $=0.0010-0.0020$ ).

To further validate the MDR results, we conducted analyses of both four-factor and two-factor models using 
Table 4: The genotype combinations of the SNP-SNP interactions in two polymorphisms with the risk of hepatocellular cancer ${ }^{\mathrm{a}}$

\begin{tabular}{|c|c|c|c|c|c|}
\hline \multicolumn{2}{|c|}{ SNP genotypes } & CON & HCC & $P$ & OR (95\% CI) \\
\hline $\begin{array}{c}\text { ERCC1 } \\
\text { rs2298881 }\end{array}$ & XPC rs1870134 & & & & \\
\hline $\mathrm{CC}$ & $\mathrm{CC}+\mathrm{GC}$ & 60 & 44 & & 1 (Ref.) \\
\hline $\mathrm{CC}$ & GG & 80 & 57 & 0.913 & $0.97(0.58-1.63)$ \\
\hline $\mathrm{CA}+\mathrm{AA}$ & $\mathrm{CC}+\mathrm{GC}$ & 119 & 73 & 0.472 & $0.84(0.52-1.36)$ \\
\hline $\mathrm{CA}+\mathrm{AA}$ & GG & 111 & 142 & 0.018 & $1.74(1.10-2.77)$ \\
\hline & & & $=0.02$ & $2.11(1$. & \\
\hline
\end{tabular}

Note: ${ }^{\text {a }} P$ for interaction was used Logistic Regession adjusted by sex and age. CON: controls; HCC: hepatocellular cancer.

Table 5: Differences of XPC gene mRNA levels in different genotypes in hepatocellular cancer and non-cancer tissues

\begin{tabular}{|c|c|c|c|c|c|c|c|c|}
\hline \multirow[b]{2}{*}{ Variable } & \multicolumn{4}{|c|}{ Non-cancer tissue } & \multicolumn{4}{|c|}{ Cancer tissue } \\
\hline & $N(\mathbf{8 6})$ & $\Delta \mathrm{Ct}($ Mean $\pm \mathrm{SD})$ & $\begin{array}{c}\text { Normalized } \\
2-\Delta \Delta C t\end{array}$ & $\boldsymbol{P}$ & $N(86)$ & $\Delta \mathrm{Ct}($ Mean $\pm \mathrm{SD})$ & $\begin{array}{c}\text { Normalized } \\
2-\Delta \Delta C t\end{array}$ & $\boldsymbol{P}$ \\
\hline $\begin{array}{c}\text { For XPC } \\
\text { mRNA }\end{array}$ & & $1.50 \pm 4.32$ & $1(0.05,19.97)$ & & & $3.58 \pm 25.77$ & $0.24(0.01,4.72)$ & 0.456 \\
\hline \multicolumn{9}{|c|}{ The effect of XPC rs1870134 genotypes to XPC mRNA } \\
\hline $\mathrm{CC}$ & 3 & $0.24 \pm 0.12$ & $1(0.92,1.09)$ & Ref. & 3 & $0.25 \pm 0.05$ & $1(0.97,1.04)$ & Ref. \\
\hline $\mathrm{GC}$ & 40 & $4.65 \pm 1.74$ & $0.05(0.01,0.16)$ & 0.587 & 40 & $6.77 \pm 38.20$ & $0.01\left(0.00,3 \times 10^{9}\right)$ & 0.772 \\
\hline GG & 43 & $0.91 \pm 0.75$ & $0.63(0.37,1.06)$ & $5 \times 10^{-5}$ & 43 & $0.81 \pm 1.25$ & $0.67(0.28,1.60)$ & 0.451 \\
\hline
\end{tabular}

the multivariate logistic regression, and found ERCC1 rs2298881-XPC rs1870134 pairwise interaction to be significant $(P=0.023, \mathrm{OR}=2.11,95 \% \mathrm{CI}=1.11-4.03$; Table 4). However, the four-factor model interaction was not reached to statistical significance $\left(P_{\text {interaction }}=0.340\right)$.

\section{Differences of XPC rs1870134 gene mRNA levels in different genotypes in hepatocellular cancer and non-cancer tissues}

For $X P C$ mRNA expression level in non-cancerous and cancerous tissues, we found $X P C$ gene was decreased in tend from non-cancer tissues to cancer tissues $(1.50 \pm 4.32$ vs. $3.58 \pm 25.77$, Table 5), although the $P$ value did not reach the statistical significance $(P=0.456)$. We further explore the potential biological significance of the XPC rs1870134 polymorphism at mRNA level (Table 5). In cancerous group, $X P C$ mRNA levels were significantly lower in subjects carrying $X P C$ rs 1870134 GG genotype compared with patients with CC genotype $\left(P=5 \times 10^{-5}\right)$.

\section{DISCUSSION}

The NER repair pathway was divided into three steps: the recognition-unwinding-incision steps. Briefly, in the recognition step, XPC-RAD23B complex or UV- damaged DNA-binding protein 2 (DDB2) could recognize DNA damage. In the unwinding step, Helicase subunits composed of XPB (ERCC3) and XPD (ERCC2) were activated, and opened the DNA duplex, then recruited XPA. XPB was a $3^{\prime}$ to $5^{\prime}$ translocase and XPD was a 5' to $3^{\prime}$ translocase. In the incision step, XPD (ERCC2) remained in the damaged DNA 3 ' region, and then XPG (ERCC5) cut on the 3' side while ERCC1-XPF (ERCC4) complex on the $5^{\prime}$ side. The damaged DNA was then repaired. Although several studies have reported an association between a single exon SNP in NER gene (such as XRCC1 Arg399Gln) with HCC, none have demonstrated a systematic and comprehensive analysis between polymorphisms in every step of NER pathways genes and HCC risk. We preliminarily screened among the NER pathways SNPs for HCC risk, and identified three risk SNPs and three protective SNPs in five genes, that is, the positive six SNPs composed of two in recognition step (XPA rs10817938 and XPC rs1870134), one in unwinding step (ERCC2 rs238417) and three in incision step (ERCC5 rs873601, ERCC1 rs2298881 and rs3212961), and one combination of a gene-gene interaction model (ERCC1 rs2298881-XPC rs1870134 pairwise) associated with HCC risk. Further functional experiments confirmed that one positive SNP XPC rs1870134 associated with $\mathrm{HCC}$ risk had an effect of polymorphism on XPC mRNA expression. 


\section{XPA rs10817938 and XPC rs1870134 in recognition step}

XPA was the first human NER protein showing a preference for binding to damaged DNA. It is also a zincbinding protein with affinity for various DNA damage [14] that functions at the core of the NER system [15]. $X P A$ is located on chromosome 9q22.3, and the promoter rs10817938 SNP we studied is located in $-2718 \mathrm{bp}$ from the transcription start site. This polymorphism has not been evaluated to be associated with the risk of any disease, but another $X P A$ promoter SNP located at $-4 \mathrm{bp}$ might change $X P A$ mRNA tertiary structure and stability, and might play a role in susceptibility to cancer [16]. The association between XPA polymorphisms with HCC risk is biologically plausible since XPA plays an important role in NER pathway while XPA protein defects were previously shown to lead to HCC susceptibility in mouse model experiments [6]. And the XPC protein also plays an important role early in the DNA damage recognition step. It tightly binds to a distorted region and changes the structure of the DNA to allow other components of the repair apparatus to enter [15]. $X P C$ gene is located on chromosome $3 \mathrm{q} 25$, and the promoter rs 1870134 SNP we studied is located at $+149 \mathrm{bp}$, which has not previously been reported to be associated with disease. In this study, we found two promoter SNPs in the $X P A$ and $X P C$ genes respectively were shown to be associated with HCC risk. As mentioned above, the promoter SNP could change the gene's function, including mRNA structure or stability, and protein expression or function, which would explain our observed association of this two promoter SNPs with HCC susceptibility.

Because the XPC gene promoter rs1870134 SNP was confirmed by the verification stage, we further performed $X P C$ mRNA expression study. We found the expression of $X P C$ gene was decreased in cancer tissues when compared with non-cancer tissues, which suggest that XPC protein functioned as protective protein in hepatocellular cancer. Then, we analyzed the effects of this SNP on XPC mRNA expression in order to clarify the possible mechanism for polymorphisms. We found the GG genotype which was associated with an increased HCC risk, showed a lower XPC mRNA expression. As XPC was a protective protein, individuals carrying risk GG genotype showed a decreased mRNA expression, causing the lower expression of this protective protein, which might be the possible mechanism for the high risk of GG genotype. The similar study reported that the rs $2298881 \mathrm{G}$ allele of $E R C C 1$ gene located in 5'-flanking region was associated with a down-regulated protein expression, and subsequent functional experiment showed this SNP could decrease the gene's promoter activity and transcription factor binding activity [17]. Thus, further functional experiments such as promoter activity and transcription factor binding activity assays should be performed to clarify the associated mechanism.

\section{ERCC2 rs238417 in unwinding step}

ERCC2, also called XPD, is an unwinding protein in NER repair that unwinds DNA from $5^{\prime}$ to $3^{\prime}$ [15]. ERCC2 gene is located on chromosome $19 \mathrm{q} 13.3$, and includes 21 SNP sites in the HapMap database. ERCC2 SNP rs238417 is located in intron 18 which was short and only $90 \mathrm{bp}$ length. Thus any polymorphism among intron 18 could largely change the second structure and mRNA stability, and the variation of rs 238417 from $\mathrm{G}$ to $\mathrm{C}$ could make $3 \mathrm{kcal} / \mathrm{mol}$ change of the minimum free energy from stable to unstable using RNAfold predicting software (http:// rna.tbi.univie.ac.at/cgi-bin/RNAfold.cgi). Peethambaram $P$ et al. studied 11 SNPs in ERCC2 gene and found this rs238417 SNP was the most significant polymorphism associated with the outcome of ovarian cancer [18]. In the present study, we demonstrated that the rs 238417 variant $\mathrm{CC}$ genotype increased the $\mathrm{HCC}$ risk by 1.77 -fold. As previous study showed, an intronic polymorphism also played an important role in mRNA splicing or protein expression [19]. Considering the length of this intron 18 was short, the short intron may cause this polymorphism to be a functional SNP. The above-mentioned might be the reason for our observed association of this rs 238417 SNP with HCC susceptibility. Further experiments are required to confirm this observation.

\section{ERCC1 rs2298881 and rs3212961 in incision step}

$\mathrm{ERCC} 1$ is an incision and repair protein that binds first to ERCC4 (XPF), then ERCC3 (XPB). This ERCC1ERCC4-ERCC3 complex cuts DNA from 5' to 3' [15]. $E R C C 1$ gene is located on chromosome 19q13.32 and any variation of ERCC1 might cause the change of ERCC1 protein, ERCC1-ERCC4-ERCC3 complex and even the whole NER pathway. Yin J et al. studied several SNPs in ERCC1 and ERCC2 and found both the rs2298881 and rs3212961 SNPs had interaction with smoking in lung cancer patients [20]. We also found that ERCC1 rs2298881 and rs3212961 were significantly associated with HCC risk. Several studies have previously reported an association with the ERCC1 promoter SNP rs2298881 and cancer risk. Indeed, Yu et al. found this rs2298881 SNP was associated with a decreased risk of lung cancer [17]. Other study showed that this SNP exhibited an increased prostate cancer risk with high fonofos exposure compared with controls [21]. In this study, we found that the ERCC1 promoter rs2298881 CA heterozygote decreased the HCC risk by a 0.64 -fold, which was consistent with the report by $\mathrm{Yu}$ et al. It was reported that the variant allele of this rs2298881 down-regulated $E R C C 1$ promoter activity, down-regulated transcription factor binding activity, and thus decreased ERCC1 protein expression with a subsequent decrease in the cancer risk [17]. Another HCC-associated ERCC1 SNP, rs3212961, located in intron 3 immediately $3^{\prime}$ to exon 3 , could affect 
transcription splicing, because ERCC1 shows several splicing variants. Although many studies showed the association of this SNP with cancer risk, the results were inconsistent. Shen et al. found that rs3212961 decreased the risk of lung cancer under a dominant model [22], while others showed that it could increase the risk for bladder cancer under a dominant model [23], as well as colorectal cancer [24]. In this study, we demonstrated that rs3212961 decreased HCC risk by 0.66 -fold under the dominant model, but the detailed underlying mechanism should be investigated, especially whether this polymorphism influence the expression of ERCC1 exon 3 or influence the selective splicing.

\section{ERCC5 rs873601 in incision step}

ERCC5 (XPG) is activated and binds the 3' region of DNA damage. This is followed by ERCC2 and ERCC5 (XPG) binding. ERCC5 rs873601 SNP is located in the 3 '-UTR. Regarding ERCC5 rs873601 SNP, a previous report showed no association with the risk of esophageal squamous cell carcinoma [25]. In single locus analysis, we found this SNP could decrease HCC risk. We speculate the way of the possibilities: 1) impact through ERCC5 mRNA and protein, or 2) impact through a third party. It is possible that this polymorphism affect protein expression and/or activity, or that they involve the same miRNA that binds the $3^{\prime}$ UTR region. Based on this result, we recently performed the mRNA expression experiment to further analyze the effects of SNP genotypes to the mRNA expression. The ERCC5 rs873601 variant genotypes associated with a decreased HCC risk showed a higher mRNA expression of ERCC5 gene (Data were not published). The mechanism of the rs873601 SNP to the mRNA level expression was not very clear now, so further functional study is required to verify this finding in future studies.

\section{Gene haplotype with HCC risk}

Combined haplotype and LD association analyses for multiple SNPs are more sensitive and powerful than SNP analysis alone [26]. We showed that the $D D B 2$ A-C-A-T haplotype of rs2029298-rs830083-rs3781619rs326222 increased the HCC risk $(\mathrm{OR}=2.29)$, while these SNPs alone had no significant association with HCC risk, indicating that the haplotype was more sensitive than a single SNP. We re-analyzed a positive SNP detected in single-site analysis of ERCC1, and observed that the twosite combination haplotype showed similar results to the entire six-site combination haplotype for both ERCC1. This simplification showed that the ERCC1 C-C haplotype of rs2298881-rs3212961 increased HCC risk, while the ERCC1 A-C haplotype decreased HCC risk.

\section{SNP-SNP interaction with HCC risk}

One of the most significant finding in our study was the multiple SNP-SNP interactions composed of ERCC1 rs2298881 and XPC rs1870134 polymorphisms, which were consistently identified by two different statistical approaches: multivariate logistic regression and MDR analyses. We found the $P$ value for " $E R C C 1$ rs2298881-XPC rs1870134-ERCC2 rs238417-ERCC5 rs873601" combination was more significant than the two-way interactions of "ERCC1 rs2298881 and XPC rs 1870134", but the four-way interaction combination was not verified by the multivariate logistic regression method, which might due to the more subgroups causing the rare genotypes. Several studies showed that the combined effect of multiple SNPs in several genes in one or more relevant DNA repair pathways could have a greater impact on pathological phenotypes than SNPs in single genes [27]. And we found the OR of "ERCC1 rs2298881 and $X P C$ rs 1870134" polymorphisms interaction was higher than the $\mathrm{OR}$ of single-locus $\left(\mathrm{OR}_{\text {interaction }}: 2.11 \mathrm{vs.} \mathrm{OR} X P C\right.$ : $1.67)$, which suggest that this two-way interaction was a superior combination model for the prediction of HCC risk. As the mechanism of these two SNPs was not very clear now, it required further functional study to verify this finding in future studies.

\section{Limitations}

However, this study still had some limitations. First, the sample size was still limited, thus restricted the probability of the subgroup analysis for variant genotypes, and also limited the interaction analysis. Second, the HCC samples were only from the surgically resected patients and not covered for patients undergoing radiotherapy or chemotherapy. However, maybe because of this, we avoided and eliminated the effect of the heterogeneity bringing from the samples sourced from various treatments. Third, the expression of the promising XPC gene in this study was only at mRNA level, while the protein expressions were also warranted to study in future research.

\section{Conclusion}

In summary, we preliminarily explored gene polymorphisms in NER pathway for predicting the risk of HCC. In the screening stage, six SNPs of five genes in three steps of NER pathways were associated with HCC risk, including three risk SNPs $(X P A$ rs 10817938, XPC rs 1870134 and $E R C C 2$ rs238417) and three protective SNPs (ERCC1 rs2298881 and rs3212961, and ERCC5 rs873601). In the verification stage, only $X P C$ rs 1870134 was verified to be associated with an increased HCC risk. Furthermore, multivariate logistic regression and MDR 
analyses consistently revealed the SNP-SNP interaction comprised of ERCC1 rs2298881 and XPC rs1870134 pairwise was associated with HCC risk. Further analysis for the effect of polymorphism on mRNA expression suggested that XPC rs1870134 GG genotype which associated with an increased HCC risk demonstrated a lower XPC mRNA expression. Future large-scale samples and functional molecular experiments are required to confirm our results.

\section{MATERIALS AND METHODS}

\section{Patients}

This research project was approved by the Ethical Committee of the First Affiliated Hospital of the China Medical University and written informed consent was obtained. The study was designed based on two-stage for the aim of "screening- verification". All clinical investigations have been conducted according to the principles expressed in the Declaration of Helsinki. This study comprised of a total of 1472 participants, among them, 570 patients (included 169 and 401 HCC patients for the screening stage and verification stage, respectively) were underwent surgical operation for HCC at the First Affiliated Hospital of China Medical University between 2012 and 2015. The participants underwent surgical operation were diagnosed by pathological confirmation with HCC according to WHO classification. A total of 902 controls were recruited from a health screening program from the Zhuanghe area, Liaoning Province, China between 2002-2012. Among them, for the screening stage, 501 controls were 1:3 frequency matched with the 169 cases of HCC according to the condition of the matched sex (1:1) and age $( \pm 5)$. And for the verification stage, 401 controls were 1:1 matched with the 401 cases of HCC by the same condition. Peripheral venous blood specimen was collected from participants and stored at $-20^{\circ} \mathrm{C}$ until use.

\section{Polymorphisms sites selected}

We selected polymorphisms using HapMap data (http://www.broadinstitute.org/mpg/haploview) referred to previously [13, 28, 29], in order to minimize the number of SNPs required to be genotyped, providing an important shortcut to carry out candidate gene association studies in a particular population. The tag SNPs were selected separately using the following criteria: 1). using Haploview by Tagger function; 2). the population of the HapMap selected CHB (Chinese Han Beijing) population; 3). the pairwise tagging with $r^{2}$ at least $\left.0.8 ; 4\right)$. a minor allele frequency was at least $5 \%$. The selection area was enlarged by $10 \mathrm{~kb}$ both upstream and downstream for all genes. FastSNP Search was used to predict the potential SNP function (leading to amino acid substitutions, altering splicing or transcription factor-binding motifs, acting as intronic enhancers) [30, 31]. A total of 39 SNPs covering eight key NER pathway genes were selected by integrating these two publicly available tools. Locations and characterizations of the selected SNPs are shown in Table 1.

\section{Genotyping}

Genomic DNA was extracted using a previously published method [32] and diluted to working concentrations of $20 \mathrm{ng} \mu \mathrm{L}^{-1}$ for genotyping. The genotyping assay for the first stage was performed by Bomiao Biological Company (Beijing, China) using the Sequenom MassARRAY platform (Sequenom, San Diego, CA, USA). In the second stage (verification stage), the assay was performed by Gene Company (Shanghai, China), using allele-specific PCR using KASPar (KASP) reagents (LGC Genomics, Hoddesdon, UK). For quality control, we repeatedly genotyped $10 \%$ of the total samples at one time in each stage, and beside these, we verified genotyping results in a third method by Huada Gene Company using direct sequencing for another $10 \%$ random samples. The concordance rate of these repeated samples reached $100 \%$, which demonstrated that the genotyping results were reliable.

\section{Quantitative RT-PCR analysis for the mRNA expression of promising genes}

The TRIzol reagent was used to isolate total RNA from approximately $50 \mathrm{mg}$ tissues in $86 \mathrm{HCC}$ specimens and their neighboring 86 non-cancer samples (Life Technologies, Carlsbad, CA, USA). The method of this part was described previously [28], and a total of $2.0 \mu \mathrm{g}$ isolated RNA was converted into cDNA using Quantscript RT Kit (Tiangen Biotech, Beijing, China). The mRNA expression of the aimed promising genes and an internal-control gene GAPDH were tested using SYBR Premix Ex Taq II (TaKaRa Biotech, Dalian, China) in an Eppendorf Mastercycler Gradient System (Eppendorf AG, Hamburg, Germany). Each reaction was performed in duplicates and blank controls without cDNA template were also tested every time. The primers were summarized in Supplementary Table S4.

The relative quantification of the mRNA level was calculated using $2^{-\Delta \Delta C t}$ method [33]. The expression levels of the aimed promising genes were normalized to those of GAPDH in each sample using the equation: $\Delta \mathrm{Ct}$ $($ delta $\mathrm{Ct})=\mathrm{Ct}_{\text {target }}-\mathrm{Ct}_{\text {GAPDH }}$. Relative expression levels were derived from $\Delta \mathrm{Ct}$-values as $2^{-\Delta \mathrm{Ct}}$. For patients stratified by the genotypes, the relative expression of patients with the common homogenous genotype were set to a unity, and the relative expression of heterogeneous and rare homogenous genotypes carriers were expressed relative to those of patients with the common homogenous genotype, thus deriving normalized $2^{-\Delta \Delta \mathrm{Ct}}$ values. 


\section{Statistical analysis}

Between-group differences in sex variability, as well as the Hardy Weinberg Equilibrium, were compared by the $\chi^{2}$ test. And analysis of variance was used for age variability. Multivariate logistic regression with adjustments for age and sex was used to show the association between selected gene polymorphisms with HCC risk. The haplotype of each gene was analyzed using SHEsis software [34]. All NER gene polymorphisms identified in the best models of gene-gene interactions were calculated using MDR software (version 3.0.2) and MDR permutation testing software (version 1.0 beta 2) [35]. The combined effect of selected SNPSNP interactions in the best model was determined by multivariate logistic regression adjusted for age and sex. The differences of relative mRNA levels between two groups were tested by the Student $t$-test. In the screening stage, $P$ value $<0.05$ was considered significant. And significance values shown for the analysis in stage 2 and merged meta data were adjusted for multiple test correction. The cut-off of significance $P$ value was used as $<0.00128(0.05 \div 39=0.00128)$ for the verification stage.

\section{Abbreviations}

SNP: single nucleotide polymorphism; OR: odds ratio; CI: confidence interval; HCC, hepatocellular cancer; NER, Nucleotide Excision Repair.

\section{ACKNOWLEDGMENTS AND GRANT SUPPORT}

This work is supported partly by grants from the National Key Basic Research Program of China (973 Program ref no. 2010CB529304), the National Natural Science Foundation of China (Ref No.31200968).

\section{CONFLICTS OF INTEREST}

All authors disclose no conflicts of interest that might bias their work.

\section{REFERENCES}

1. Bosetti C, Turati F, La Vecchia C. Hepatocellular carcinoma epidemiology. Best Pract Res Clin Gastroenterol. 2014; 28:753-770.

2. Ferlay J, Shin HR, Bray F, Forman D, Mathers C, Parkin DM. Estimates of worldwide burden of cancer in 2008: GLOBOCAN 2008. Int J Cancer. 2010; 127:2893-2917.

3. Nahon P, Zucman-Rossi J. Single nucleotide polymorphisms and risk of hepatocellular carcinoma in cirrhosis. J Hepatol. 2012; 57:663-674.
4. Goode EL, Ulrich CM, Potter JD. Polymorphisms in DNA repair genes and associations with cancer risk. Cancer Epidemiol Biomarkers Prev. 2002; 11:1513-1530.

5. Liu J, He C, Xing C, Yuan Y. Nucleotide excision repair related gene polymorphisms and genetic susceptibility, chemotherapeutic sensitivity and prognosis of gastric cancer. Mutat Res Fundam Mol Mech Mutagen. 2014; 765C:11-21.

6. Ishikawa T, Zhang SS, Qin X, Takahashi Y, Oda H, Nakatsuru Y, Ide F. DNA repair and cancer: lessons from mutant mouse models. Cancer Sci. 2004; 95:112-117.

7. Shao N, Li J, Xu B, Wang Y, Lu X, Feng N. Role of the functional variant $(-652 \mathrm{~T}>\mathrm{G})$ in the XRCC4 promoter in prostate cancer. Mol Biol Rep. 2014; 41:7463-70. doi: 10.1007/s11033-014-3636-1.

8. Wei ZH, Guo WH, Wu J, Suo WH, Fu GH. A nonsense mutation in the Xeroderma pigmentosum complementation group F (XPF) gene is associated with gastric carcinogenesis. Gene. 2014; 537:238-244.

9. Liu F, Li B, Wei Y, Yan L, Wen T, Zhao J, Xu M. XRCC1 genetic polymorphism Arg399Gln and hepatocellular carcinoma risk: a meta-analysis. Liver Int. 2011; 31: 802-809.

10. Xie T, Wang ZG, Zhang JL, Liu H. X-ray repair crosscomplementing group 1 polymorphisms and hepatocellular carcinoma: a meta-analysis. World J Gastroenterol. 2012; 18:4207-4214.

11. Wu KG, He XF, Li YH, Xie WB, Huang X. Association between the XPD/ERCC2 Lys751Gln polymorphism and risk of cancer: evidence from 224 case-control studies. Tumour Biol. 2014; 35:11243-59. doi: 10.1007/s13277014-2379-x.

12. Gulnaz A, Sayyed AH, Amin F, Khan A, Aslam MA, Shaikh RS, Ali M. Association of XRCC1, XRCC3, and $\mathrm{XPD}$ genetic polymorphism with an increased risk of hepatocellular carcinoma because of the hepatitis B and C virus. Eur J Gastroenterol Hepatol. 2013; 25:166-179.

13. Vineis P, Manuguerra M, Kavvoura FK, Guarrera S, AllioneA, Rosa F, Di Gregorio A, Polidoro S, Saletta F, Ioannidis JP, Matullo G. A field synopsis on low-penetrance variants in DNA repair genes and cancer susceptibility. J Natl Cancer Inst. 2009; 101:24-36.

14. Asahina H, Kuraoka I, Shirakawa M, Morita EH, Miura N, Miyamoto I, Ohtsuka E, Okada Y, Tanaka K. The XPA protein is a zinc metalloprotein with an ability to recognize various kinds of DNA damage. Mutat Res. 1994; 315:229-237.

15. Wood RD. DNA damage recognition during nucleotide excision repair in mammalian cells. Biochimie. 1999; 81:39-44.

16. Ding D, Zhang Y, Yu H, Guo Y, Jiang L, He X, Ma W, Zheng W. Genetic variation of XPA gene and risk of cancer: a systematic review and pooled analysis. Int J Cancer. 2012; 131:488-496. 
17. Yu D, Zhang X, Liu J, Yuan P, Tan W, Guo Y, Sun T, Zhao D, Yang M, Liu J, Xu B, Lin D. Characterization of functional excision repair cross-complementation group 1 variants and their association with lung cancer risk and prognosis. Clin Cancer Res. 2008; 14:2878-2886.

18. Peethambaram P, Fridley BL, Vierkant RA, Larson MC, Kalli KR, Elliott EA, Oberg AL, White KL, Rider DN, Keeney GL, Cunningham JM, Hartmann LC, Goode EL. Polymorphisms in ABCB1 and ERCC2 associated with ovarian cancer outcome. Int J Mol Epidemiol Genet. 2011; 2:185-195.

19. Wang D, Guo Y, Wrighton SA, Cooke GE, Sadee W. Intronic polymorphism in CYP3A4 affects hepatic expression and response to statin drugs. Pharmacogenomics J. 2011; 11:274-286.

20. Yin J, Vogel U, Ma Y, Qi R, Wang H, Yue L, Liang D, Wang C, Li X, Song T. HapMap-based study of a region encompassing ERCC1 and ERCC2 related to lung cancer susceptibility in a Chinese population. Mutat Res. 2011; 713:1-7.

21. Barry KH, Koutros S, Andreotti G, Sandler DP, Burdette LA, Yeager M, Beane Freeman LE, Lubin JH, Ma X, Zheng T, Alavanja MC, Berndt SI. Genetic variation in nucleotide excision repair pathway genes, pesticide exposure and prostate cancer risk. Carcinogenesis. 2012; 33:331-337.

22. Shen M, Berndt SI, Rothman N, Demarini DM, Mumford JL, He X, Bonner MR, Tian L, Yeager M, Welch R, Chanock S, Zheng T, Caporaso N, Lan Q. Polymorphisms in the DNA nucleotide excision repair genes and lung cancer risk in Xuan Wei, China. Int J Cancer. 2005; 116:768-773.

23. Garcia-Closas M, Malats N, Real FX, Welch R, Kogevinas M, Chatterjee N, Pfeiffer R, Silverman D, Dosemeci M, Tardon A, Serra C, Carrato A, Garcia-Closas R, et al. Genetic variation in the nucleotide excision repair pathway and bladder cancer risk. Cancer Epidemiol Biomarkers Prev. 2006; 15:536-542.

24. Skjelbred CF, Saebo M, Nexo BA, Wallin H, Hansteen IL, Vogel U, Kure EH. Effects of polymorphisms in ERCC1, ASE-1 and RAI on the risk of colorectal carcinomas and adenomas: a case control study. BMC cancer. 2006; 6:175.

25. Zhu ML, Shi TY, Hu HC, He J, Wang M, Jin L, Yang YJ, Wang JC, Sun MH, Chen H, Zhao KL, Zhang Z, Chen HQ, et al. Polymorphisms in the ERCC5 gene and risk of esophageal squamous cell carcinoma (ESCC) in Eastern Chinese populations. PLoS One. 2012; 7:e41500.

26. Yin J, Vogel U, Ma Y, Qi R, Wang H. HapMap-based study of the DNA repair gene ERCC2 and lung cancer susceptibility in a Chinese population. Carcinogenesis. 2009; 30:1181-1185.

27. Ricceri F, Matullo G, Vineis P. Is there evidence of involvement of DNA repair polymorphisms in human cancer? Mutat Res. 2012; 736:117-121.

28. Xu Q, Chen MY, He CY, Sun LP, Yuan Y. Promoter polymorphisms in trefoil factor 2 and trefoil factor 3 genes and susceptibility to gastric cancer and atrophic gastritis among Chinese population. Gene. 2013; 529:104-112.

29. Gong Y, He C, Duan Z, Sun L, Xu Q, Xing C, Yuan Y. Association of two ERCC4 tagSNPs with susceptibility to atrophic gastritis and gastric cancer in Chinese. Gene. 2013; 519:335-342.

30. Tabor HK, Risch NJ, Myers RM. Candidate-gene approaches for studying complex genetic traits: practical considerations. Nat Rev Genet. 2002; 3:391-397.

31. Yuan HY, Chiou JJ, Tseng WH, Liu CH, Liu CK, Lin YJ, Wang HH, Yao A, Chen YT, Hsu CN. FASTSNP: an always up-to-date and extendable service for SNP function analysis and prioritization. Nucleic Acids Res. 2006; 34:W635-641.

32. Xu Q, Yuan Y, Sun LP, Gong YH, Xu Y, Yu XW, Dong NN, Lin GD, Smith PN, Li RW. Risk of gastric cancer is associated with the MUC1 $568 \mathrm{~A} / \mathrm{G}$ polymorphism. Int J Oncol. 2009; 35:1313-1320.

33. Livak KJ, Schmittgen TD. Analysis of relative gene expression data using real-time quantitative PCR and the 2(-Delta Delta C(T)) Method. Methods. 2001; 25:402-408.

34. Li Z, Zhang Z, He Z, Tang W, Li T, Zeng Z, He L, Shi Y. A partition-ligation-combination-subdivision EM algorithm for haplotype inference with multiallelic markers: update of the SHEsis (http://analysis.bio-x.cn). Cell Res. 2009; 19:519-523.

35. Hahn LW, Ritchie MD, Moore JH. Multifactor dimensionality reduction software for detecting gene-gene and gene-environment interactions. Bioinformatics. 2003; 19:376-382. 